\title{
34. GRAVITY AND MAGNETIC SIGNATURE OF BROKEN RIDGE, SOUTHEAST INDIAN OCEAN ${ }^{1}$
}

\author{
Garry D. Karner, ${ }^{2}$ Neal W. Driscoll, ${ }^{2,3}$ and John W. Peirce ${ }^{4}$
}

\begin{abstract}
Broken Ridge is a shallow-water carbonate platform of Late Cretaceous age that was uplifted and truncated during the initiation of the Southeast Indian Ridge in the middle Eocene. Since pre-rift basement is not clearly imaged in seismic-reflection data or penetrated by Leg 121 drilling, magnetic data were used to constrain the depth of the pre-rift basement using the Werner deconvolution magnetic-depth estimation technique. Our results show that magnetic basement is gently dipping to the north with maximum sediment thicknesses of 1000-1500 m. Further, magnetic depth estimates suggest that the steep southerly escarpment of Broken Ridge consists of basaltic rocks. Predicted basement dip increases markedly toward the southern escarpment, indicating a total variation of basement topography across Broken Ridge of $\approx 2000-2800$ m. Gravity data across Broken Ridge were used to (1) define the regional topography of the Moho across Broken Ridge, and (2) determine the coupling between pre-rift oceanic crust of Broken Ridge and new (post-rift) oceanic crust of the Southeast Indian Ridge system. The amplitude of the complete Bouguer gravity anomaly (i.e., corrected for the three-dimensional gravitational effect of the bathymetry) increases from north to south across Broken Ridge. The change in gravity anomaly amplitude is $\approx 60 \mathrm{mgal}$ and implies a change in Moho relief across Broken Ridge of $\approx 2700 \mathrm{~m}$. Moho relief across Broken Ridge, as inferred from the gravity analysis, is similar in shape to the basement relief as estimated from Werner deconvolution. We conclude that the Moho relief beneath Broken Ridge is elevated beneath the highest part of the ridge instead of being depressed as required by an Airy compensation model. Thermal and mechanical modeling of both the topography and free-air gravity anomaly of Broken Ridge suggests that the basement and Moho topographies are consistent with Broken Ridge being a flexural uplift produced by the unloading of the lithosphere during extension. Our modeling also suggests that the region between the escarpment and the new ocean/old ocean boundary is tectonically equivalent to a "rift basin" with a maximum depth of $\approx 1.5 \mathrm{~km}$ below the present-day seafloor. We interpret the uplift of the post-rift crust of the Southeast Indian Ridge system immediately adjacent to the rift basin as a consequence of differential subsidence between Broken Ridge and the Southeast Indian Ridge while they were mechanically coupled. The mechanical support of Broken Ridge and the uplift of the Southeast Indian Ridge ocean crust both attest to a finite flexural strength of the lithosphere during and after rifting despite localized fracturing of the crust by crustal-scale normal faults and high heat-flow regimes associated with the establishment of the Southeast Indian Ridge spreading system.
\end{abstract}

\section{INTRODUCTION}

The objectives for Ocean Drilling Program (ODP) Leg 121 drilling at Broken Ridge (Fig. 1) were to (1) determine the tectonic significance of the total sedimentary section in terms of pre-, syn-, and post-rift deposits, and (2) use the drilling results to constrain the timing and duration of Broken Ridge rifting and the amplitude of vertical motions of the lithosphere engendered by this extension. To address these points completely requires information on the regional topographic relief of the basement and Moho. Acoustic basement, as imaged by single-channel seismic-reflection data, might represent indurated sedimentary rocks such as carbonates, tuffs, and intercalated cherts rather than the surface of oceanic crust (i.e., volcanic basement). Neither Leg 121 nor Deep Sea Drilling Project (DSDP) Site 255 drilling on Broken Ridge encountered basement rocks. However, dredging of the southern escarpment of Broken Ridge during the Robert D. Conrad cruise 2708 (RC2708) pre-drilling survey recovered oceanic island-type basalts indicative of thickened oceanic crust (Duncan, this volume).

\footnotetext{
${ }^{1}$ Weissel, J., Peirce, J., Taylor, E., Alt, J., et al., 1991. Proc, ODP, Sci. Results, 121: College Station, TX (Ocean Drilling Program).

${ }^{2}$ Lamont-Doherty Geological Observatory of Columbia University, Palisades, NY 10964, U.S.A.

${ }^{3}$ Also at Department of Geological Sciences, Columbia University, Palisades, NY 10964, U.S.A.

${ }^{4}$ Petro Canada, Calgary, Alberta T2P 3E3, Canada.
}

There presently exists a major controversy concerning the mechanisms responsible for the formation and isostatic support of rift flanks. As Broken Ridge is the northerly flank of a mid-Eocene rift, it presents an excellent locale for investigating this issue. Broken Ridge is potentially the result of (1) the flexural rebound of the Broken Ridge region during extension of the lithosphere as described by Weissel and Karner (1989); (2) topographic uplift supported by rift-induced heating, perhaps as small-scale convection (Buck, 1986) or extension of the lithospheric mantle (Royden and Keen, 1980); (3) topographic support by thickened crust (i.e., the classic Airy model for isostatic compensation); or (4) some combination of all three mechanisms. In each case, the crust/mantle boundary (i.e., Moho topographic relief) will have a unique shape determined by the isostatic support of the surface topography. Although sonobuoys were used to determine the sediment velocity structure of Broken Ridge, the restricted penetration of the single-channel seismic source allowed imaging of only the sediment structure (Driscoll et al., 1989). Consequently, no direct information exists on the local shape of the Moho, although earlier interpretations of the regional structure of Broken Ridge using seismic-refraction data suggest that the crust is generally 18-20 $\mathrm{km}$ thick (Francis and Raitt, 1967; MacKenzie et al., 1980).

The purpose of this paper is to (1) interpret magnetic data collected during the RC2708 pre-drilling survey of Broken Ridge using the Werner deconvolution technique to estimate the depth to "magnetic" basement, and (2) estimate Moho topography by removing the three-dimensional gravity effect of Broken Ridge from the observed free-air gravity anomaly. By assuming that 


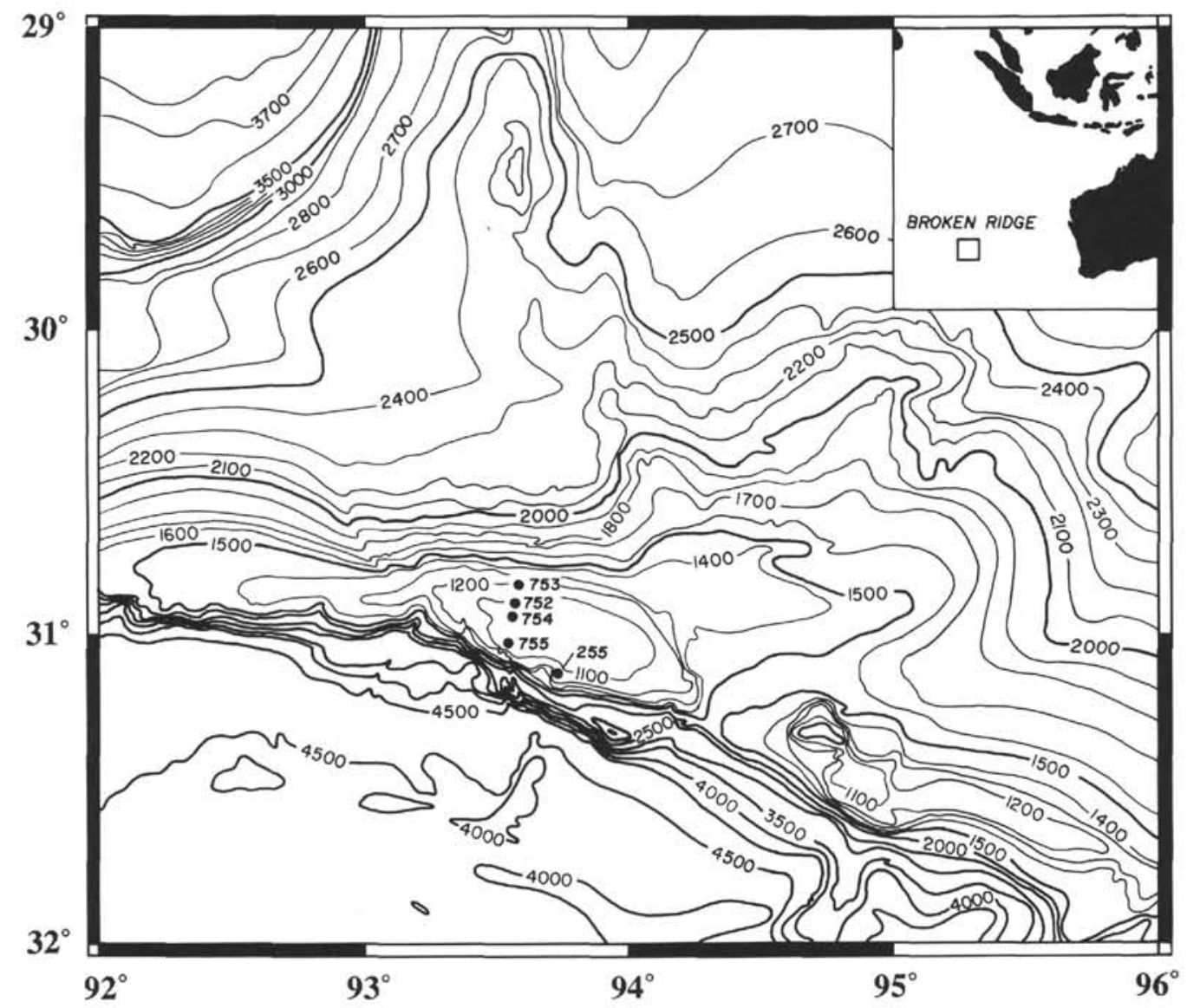

Figure 1. General bathymetry of the southeastern Indian Ocean, showing the location of Broken Ridge, Leg 121 sites, and DSDP Site 255. The boundary between the post-rift oceanic crust of the Southeast Indian Ridge system and the thickened pre-rift oceanic crust of Broken Ridge is approximately delineated by the $4000-\mathrm{m}$ isobath. North of this boundary, the contour interval is $100 \mathrm{~m}$; south, it is $500 \mathrm{~m}$.

magnetic basement can be approximated as the top of pre-rift crust, then the geometric relationship between the top of oceanic crust and Moho can feasibly distinguish between the various models proposed for the formation of Broken Ridge.

\section{FREE-AIR GRAVITY AND MAGNETIC RESPONSE OF BROKEN RIDGE}

The area of interest for this study was limited to that region having ship-track coverage adequate to represent the data as a two-dimensional distribution. Given the gravity data coverage defined by Conrad cruises RC2708 and RC1105 and Eltanin cruise EEL48 (Fig. 2), bathymetric and free-air gravity anomaly data were gridded at a $2^{\prime} \times 2^{\prime}$ spacing using an algorithm based on continuous curvature splines (e.g., Smith and Wessel, 1990). The resulting contour maps of bathymetry and free-air gravity anomaly over the central portion of Broken Ridge are shown in Figures $3 \mathrm{~A}$ and $3 \mathrm{~B}$, respectively.

Figure 4 shows the quality of topography, free-air gravity, and magnetic data along dip lines projected perpendicular to the trend of Broken Ridge. The 160-to 180 -mgal peak-to-trough amplitude of the free-air gravity anomaly across Broken Ridge reflects, in part, an "edge effect" because of the change in crustal thickness from Broken Ridge (18-20 km) to the more typical oceanic crustal thickness of 5-8 km associated with the Southeast Indian Ridge. However, this gravity range is particularly large relative to the 3000 - to $3500-\mathrm{m}$ topographic relief across the southern-facing escarpment at Broken Ridge, and suggests that other significant contributions to the gravity anomaly are present.
The peak-to-trough amplitude of the total magnetic anomaly across Broken Ridge is typically $800-1000 \mathrm{nT}$ (nanoteslas) and is primarily due to topographic variations across the ridge.

\section{SEISMIC VELOCITY SIGNATURE OF BROKEN RIDGE}

The seismic-reflection profiles of Broken Ridge and depth estimates of magnetic basement obtained from Werner deconvolution are best compared when the seismic display has been converted to depth. Velocity solutions from 15 sonobuoys deployed during the pre-drilling survey of Broken Ridge (Driscoll et al., 1989), combined with Leg 121 laboratory compressionalwave velocity measurements and downhole sonic measurements, were used to define the velocity structure of the sediments comprising Broken Ridge. These data were used to convert seismic dip lines 6,10 and 16, and 20 from time to depth sections.

Velocity determinations from sonobuoys 12,17 , and 50 are shown in Figure 5 superposed onto seismic-reflection line 20 after correcting for water depth (Fig. 1). Our velocity results are consistent with previously determined velocity solutions from the Eltanin cruise 48 sonobuoys deployed on the northern slope of Broken Ridge. The velocity profiles shown in Figure 5 show a number of discrete velocity jumps that step from $\approx 2.2 \mathrm{~km} / \mathrm{s}$ to $\approx 4.5$ $\mathrm{km} / \mathrm{s}$ in less than $200 \mathrm{~ms}$ two-way traveltime (TWT) (sonobuoys 17 and 50; Fig. 5). The change in lithology from limestones and cherts to nannofossil ooze across the angular unconformity on the summit of Broken Ridge is associated with a significant increase in seismic velocity from $1.7 \mathrm{~km} / \mathrm{s}$ to $>3.5 \mathrm{~km} / \mathrm{s}$ (sonobuoy 12 ; Fig. 


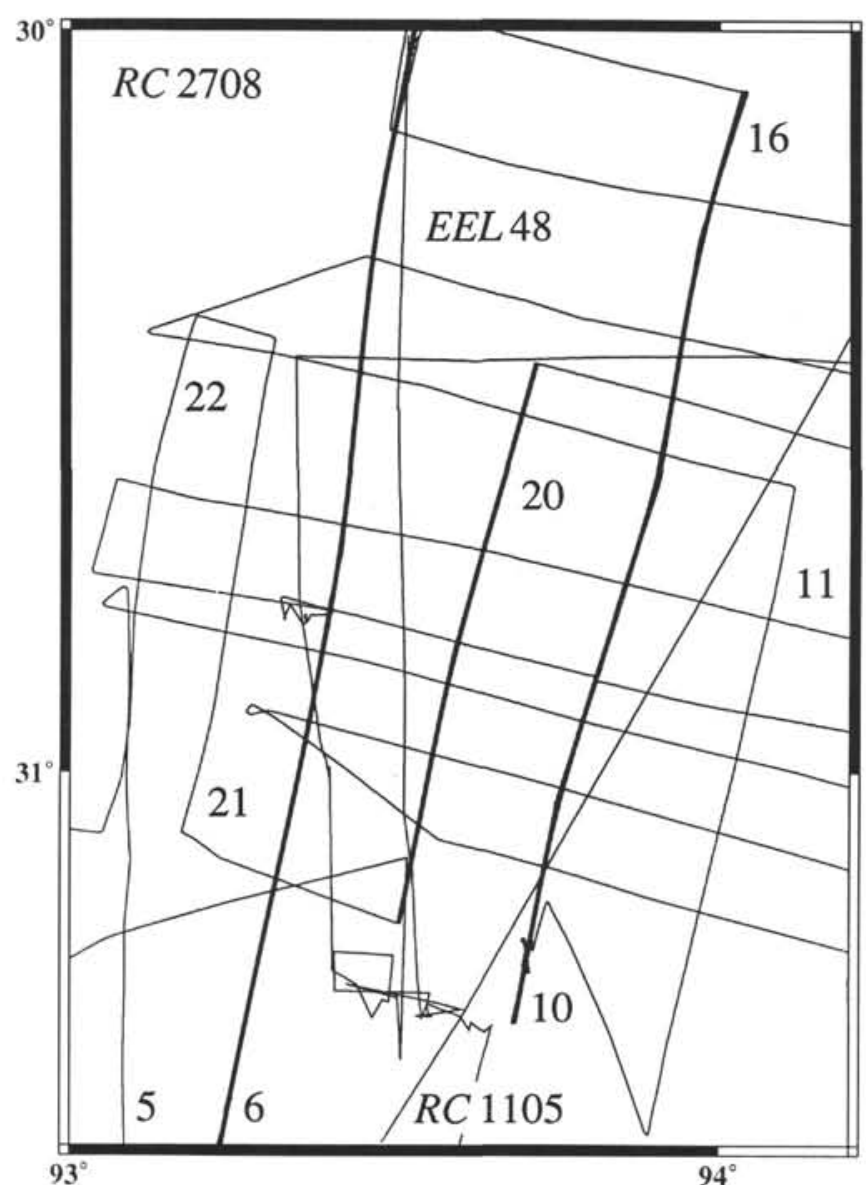

Figure 2. Ship tracks used in this study to define a two-dimensional grid of gravity, magnetics, and bathymetry of Broken Ridge. The three bold lines represent RC2708 seismic lines 6,20 , and 10 and 16, the tracks used for Werner deconvolution.

$5)$. Further, there is an increase in seismic velocity from $\approx 2.2 \mathrm{~km} / \mathrm{s}$ to $\approx 3.5 \mathrm{~km} / \mathrm{s}$ toward the base of the prograding carbonate sequence.

Averaged laboratory-determined velocities for the Turonian to upper Santonian section are significantly lower than those obtained from the sonobuoy data $(2.85 \mathrm{~km} / \mathrm{s}$ compared to $4.5 \mathrm{~km} / \mathrm{s})$. As this section contains interspersed high-velocity chert layers, the intervening material represents low-velocity zones and as such, is not readily apparent in the sonobuoy data. Thus, for the basal Turonian to upper Santonian sedimentary section, we calculated an average compressional-wave velocity of $3.4 \mathrm{~km} / \mathrm{s}$ based on both the sonobuoy solutions and the ODP laboratory measurements.

\section{DEPTH ESTIMATES OF MAGNETIC BASEMENT: WERNER DECONVOLUTION}

Magnetic data is often used to estimate the depth of magnetic basement in sedimentary basins and passive continental margins (e.g., Peters, 1949; Grant and West, 1965; Klitgord and Behrendt, 1979). This is possible because, in general, the sediments within a basin have relatively weak magnetic susceptibilities compared with those of crystalline/volcanic basement at the base of the sediment column. As volcanic basement was not drilled during Leg 121, we have applied the Werner deconvolution technique (Werner, 1953; Hsü and Tilbury, 1977) to estimate the depth to magnetic basement across Broken Ridge. Further, because this technique is rarely used for academic purposes, we present a full description of the underlying theory of Werner deconvolution in the Appendix.

The projected total magnetic data from lines 6,10 and 16 , and 20 were used for Werner deconvolution because of the proximity of the lines to the drilling sites. The data window, as explained in the Appendix, contains 11 points and steps through the profile at successively greater data spacings. Each analysis for a given window spacing focuses on a different wavelength and hence, depth to source. Werner deconvolution depth estimates are presented in Figures $6 \mathrm{~A}-6 \mathrm{C}$ and are marked by solid circles. The circle diameter is scaled to the intensity of magnetization. Depth estimates ranged from $500 \mathrm{~m}$ to $10 \mathrm{~km}$.

To interpret these results requires knowledge of the role of the data window. For a given pass and data spacing, 11 points are used to define a depth, magnetization intensity, and magnetization dip estimate. As the window is made wider, deeper magnetic sources potentially can be recognized. Depth estimates for a "true" shallow source will usually be biased to deeper depths for increasing window lengths. If the deconvolution is successful in defining a "real" magnetic body, then depth estimates should define the depth range of an interface or the upper boundary of the dike. Another important factor to keep in mind when interpreting the depth estimates from Werner deconvolution is the type of model assumed to be representative of the magnetic source (i.e., dike or interface). In general, the interface model is useful in defining the upper "edges" of the source but fails to define its depth-extent. Further, depth estimates of minor features tend to be underestimated. In contrast, the dike model is generally successful in defining the depth-extent of both major and minor features. Consequently, for this analysis, both interface and dike depth estimates have been superposed onto the depth-converted seismicreflection data of Broken Ridge in an effort to define the upper edges and depth-extent of magnetic sources comprising the magnetic basement. However, in doubling the actual number of depth estimates, we are sacrificing statistical coherency to enhance our ability to define the outline of the magnetic sources.

In all three cases, the southern boundary of Broken Ridge appears to represent magnetic basement and, presumably, oceanic crust (Figs. 6A-6C). The rapid change in intensity of magnetization (i.e., the diameter of the solid circles) seen in Figures $6 \mathrm{~A}-6 \mathrm{C}$ appears to correlate with the transition from coherent reflections associated with Turonian to middle Eocene limestones and cherts to a region of generally incoherent reflections. We interpret this abrupt change in magnetic intensity as the top of magnetic basement and is delineated in Figure 6 as a thick, solid line. The large scatter of depth estimates and magnetization intensities obtained from the northerly section of line 6 has not been included in the mapping of magnetic basement (Fig. 6A). It is interesting to note, however, that the seismic-reflection data does indicate disruption of the sedimentary column in this region, perhaps due to post-rifting magmatic intrusions. If so, these intrusions would likely form magnetic basement and obscure the "real" but deeper magnetic basement.

In addition to the depth estimates derived using Werner deconvolution, additional estimates were also calculated graphically using the Peters (1949) half-slope method (open circles, Figs. $6 \mathrm{~B}-6 \mathrm{C}$ ). The results obtained from line 20 and lines 10 and 16 confirm the results of the Werner deconvolution and support our interpreted position for magnetic basement. Anomalies on line 6 were unsuitable for graphical analysis. Further, a common problem with magnetic data is the aliasing introduced during digitization. This aliasing is reflected through Werner deconvolution as anomalously shallow depth estimates. Depth estimates shallower than the observed bathymetry have been deleted from Figure 6 .

From the depth estimates shown in Figures $6 \mathrm{~A}-6 \mathrm{C}$, the maximum thickness of pre-, syn-, and post-rift sediments is $1000-1500$ 
A

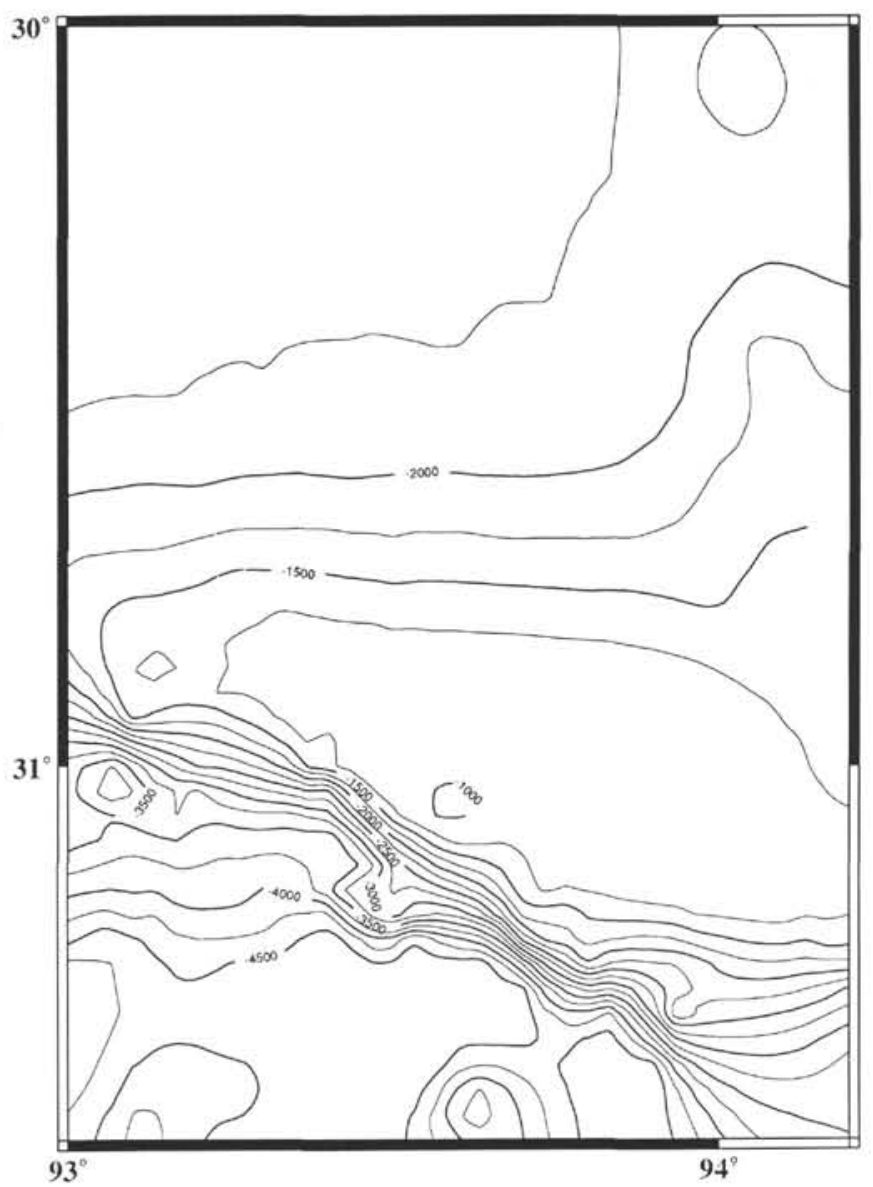

B

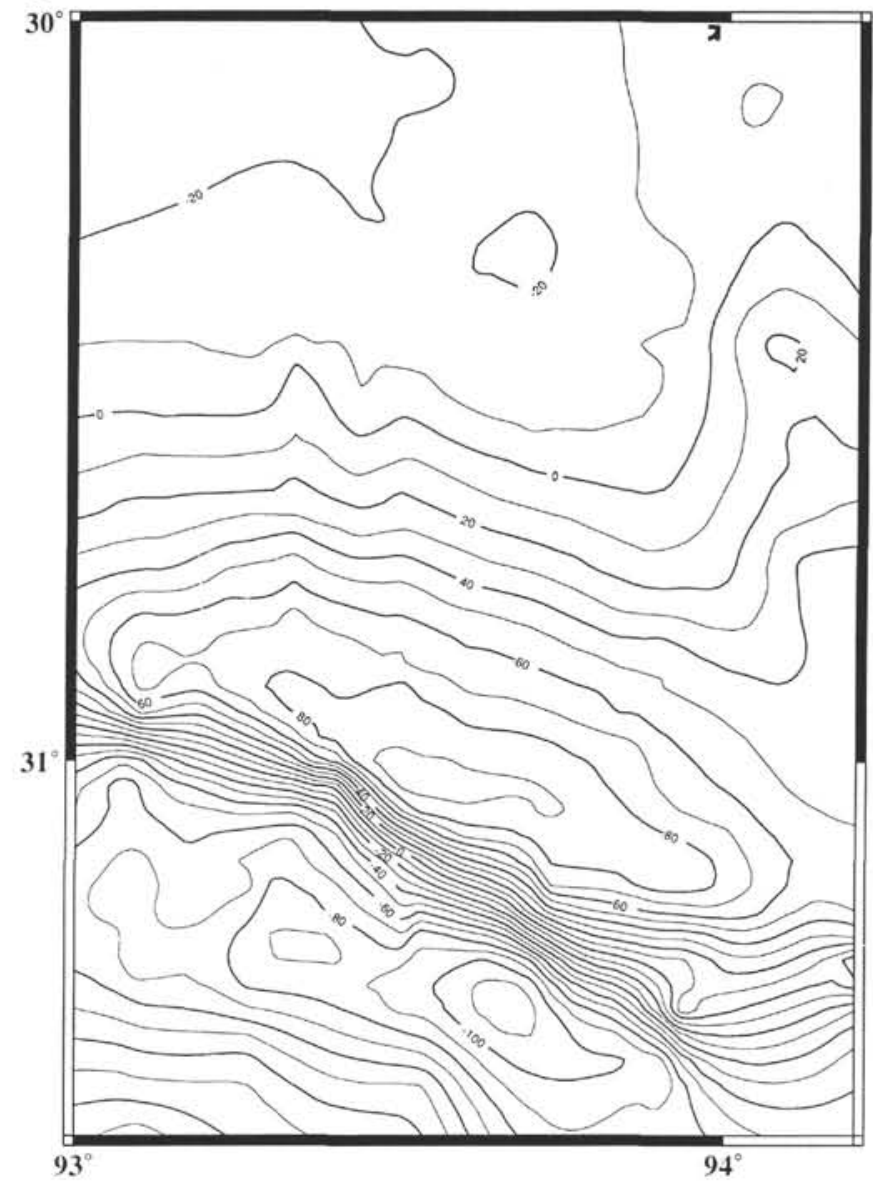

Figure 3. The $2^{\prime} \times 2^{\prime}$ grids obtained using a continuous curvature spline algorithm for the study area. A. Topography (contour interval $=250 \mathrm{~m}$ ). B. Free-air gravity (contour interval $=10 \mathrm{mgal}$ ).

m. The predicted basement shows a gentle northerly dip that increases in dip markedly toward the southern escarpment of Broken Ridge. The relative change in basement depth across Broken Ridge is $\approx 2000-2800 \mathrm{~m}$.

\section{CALCULATION OF THREE-DIMENSIONAL GRAVITY EFFECTS}

Parker (1973) determined the gravity effect of a general topographic surface in terms of a series of Fourier transforms, viz.,

$F[\Delta g(x, y)]=-2 \pi \gamma \Delta \rho e^{-\overline{|k|} z_{o}} \sum_{n=1}^{\infty} \frac{|\bar{k}|^{n-1}}{n !} F\left[h^{n}(x, y)\right]$,

where $x$ and $y$ refer to the spatial coordinates in the space domain, $\left[|k|=\sqrt{k_{x}+k_{y}}\right]$ is the radial wave number with $k_{\mathrm{x}}$ and $k_{\mathrm{y}}$ being the equivalent wave numbers in the $x$ and $y$ directions, respectively, $\gamma$ is Newton's gravitational constant, $\Delta \rho$ is the density contrast across the interface that has topography $h(x, y), z_{o}$ is the depth of the unperturbed topography, and $F$ is the Fourier transform operator.

The geographical grids used to define $h(x, y)$ and $\Delta g(x, y)$ are shown in Figures 7A and 7B, respectively. The grid is expressed in terms of minutes from a local origin defined at the lower lefthand corner of the study region. The contour interval is $250 \mathrm{~m}$ and $10 \mathrm{mgal}$ for $h(x, y)$ and $\Delta \mathrm{g}(x, y)$, respectively. Assuming a constant topographic (and crustal) density of $2.8 \mathrm{~g} / \mathrm{cm}^{3}$, water density of $1.03 \mathrm{~g} / \mathrm{cm}^{3}$, an unperturbed depth of the topography $z_{o}$ of $2.5 \mathrm{~km}$, and 4 terms for the summation in equation 1 , the gravity effect of the topography can be calculated (Fig. 8A). The longwavelength nature of the resulting gravity is due primarily to the "low-pass" filtering effected by upward continuation. The gravity difference, $\Delta g_{\text {observed }}(x, y)-\Delta g_{\text {predicted }}(x, y)$, is shown in Figure $8 \mathrm{~B}$; given that the most important long-wavelength density contrast other than the bathymetry is Moho, then Figure $8 \mathrm{~B}$ should represent the gravity effect of the Moho topography. In many ways, the gravity difference shown in Figure $8 \mathrm{~B}$ is analogous to the complete (i.e., terrain-corrected) Bouguer anomaly used for gravity interpretations of mountain systems. We have chosen a topographic density that is more appropriate for the crust rather than the sediment and therefore may overestimate the gravity due to the topography. However, as can be seen from the seismic-refraction velocities shown in Figure 5, the sediment velocity rapidly increases from $1.8-2 \mathrm{~km} / \mathrm{s}$ to $>4-5 \mathrm{~km} / \mathrm{s}$ over a $200-500 \mathrm{~ms}$ depth range. Presumably, sediment density paces this rapid change in seismic velocity. Thus, the relative small amount of low-density sediment that comprises the backbone of Broken Ridge should have minimal effect on the gravity difference shown in Figure $8 \mathrm{~B}$.

Figure 8B shows two main features: (1) a gentle increase in gravity from the northerly extremities of Broken Ridge to its southern escarpment, with a pronounced gravity positive at, and parallel to, the summit of Broken Ridge, and (2) a rapid decrease and then increase in gravity that correlates with the region between the escarpment and the boundary between the post-rift 

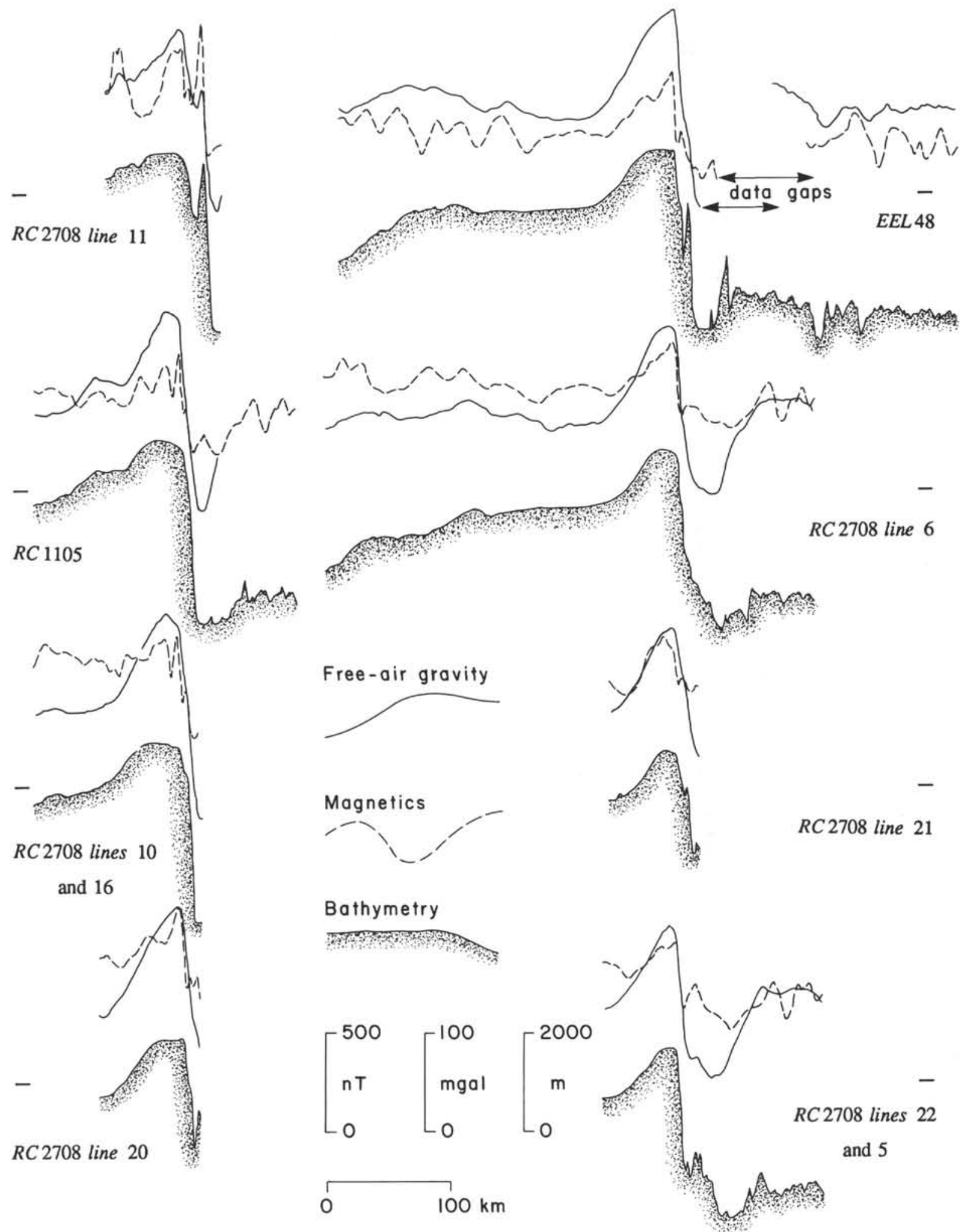

Figure 4. Gravity, magnetic, and bathymetry profiles projected perpendicular to the regional trend of Broken Ridge. These profiles represent the dip-line data used to construct the grids shown in Figures 3A and 3B. 


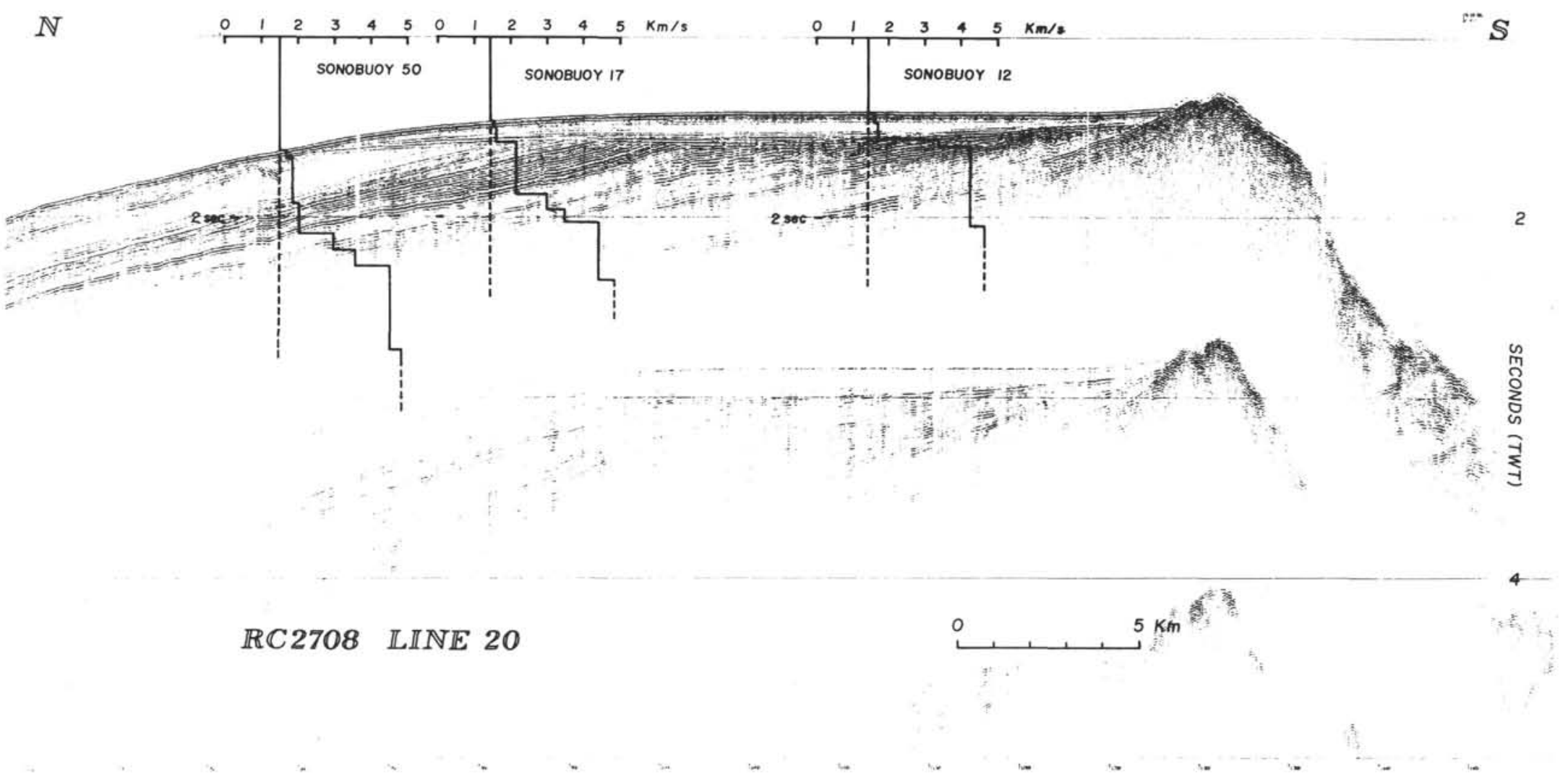

Figure 5. Sonobuoy velocity solutions projected onto seismic line 20 , correcting for changes in water depth. These and other sonobuoys were used to convert the seismic-reflection displays from time to depth. 

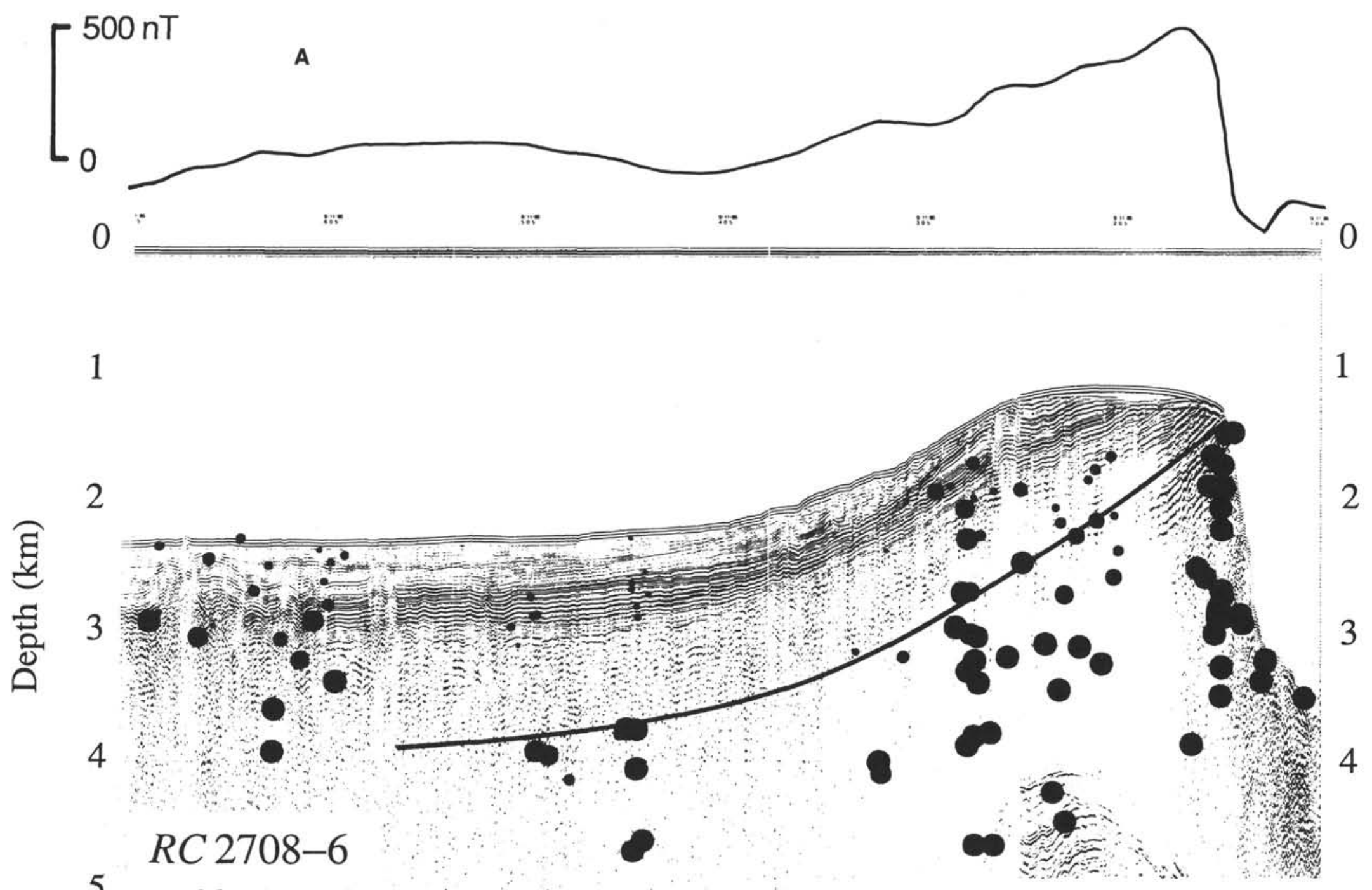

5

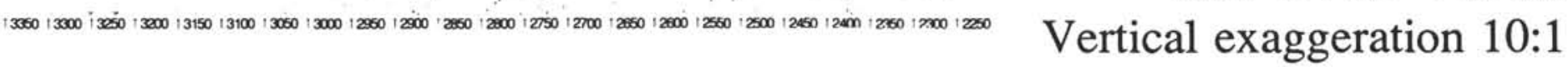

Figure 6. Magnetic depth estimates (solid circles) across Broken Ridge using Werner deconvolution superposed onto depth-converted seismic reflection profiles. Depth estimates obtained by Peters half-slope method are shown as open circles and error bars (1- $\sigma$ standard deviation). The diameters of the solid circles are scaled to the estimated intensity of magnetization. Respective magnetic anomalies (relative to an IGRF-75 reference field) are also displayed for each profile. A. Seismic line 6. B. Seismic line 20. C. Seismic lines 10 and 16. The interpreted position of basement is based on both the magnetic depth estimates and seismic-reflection data. 

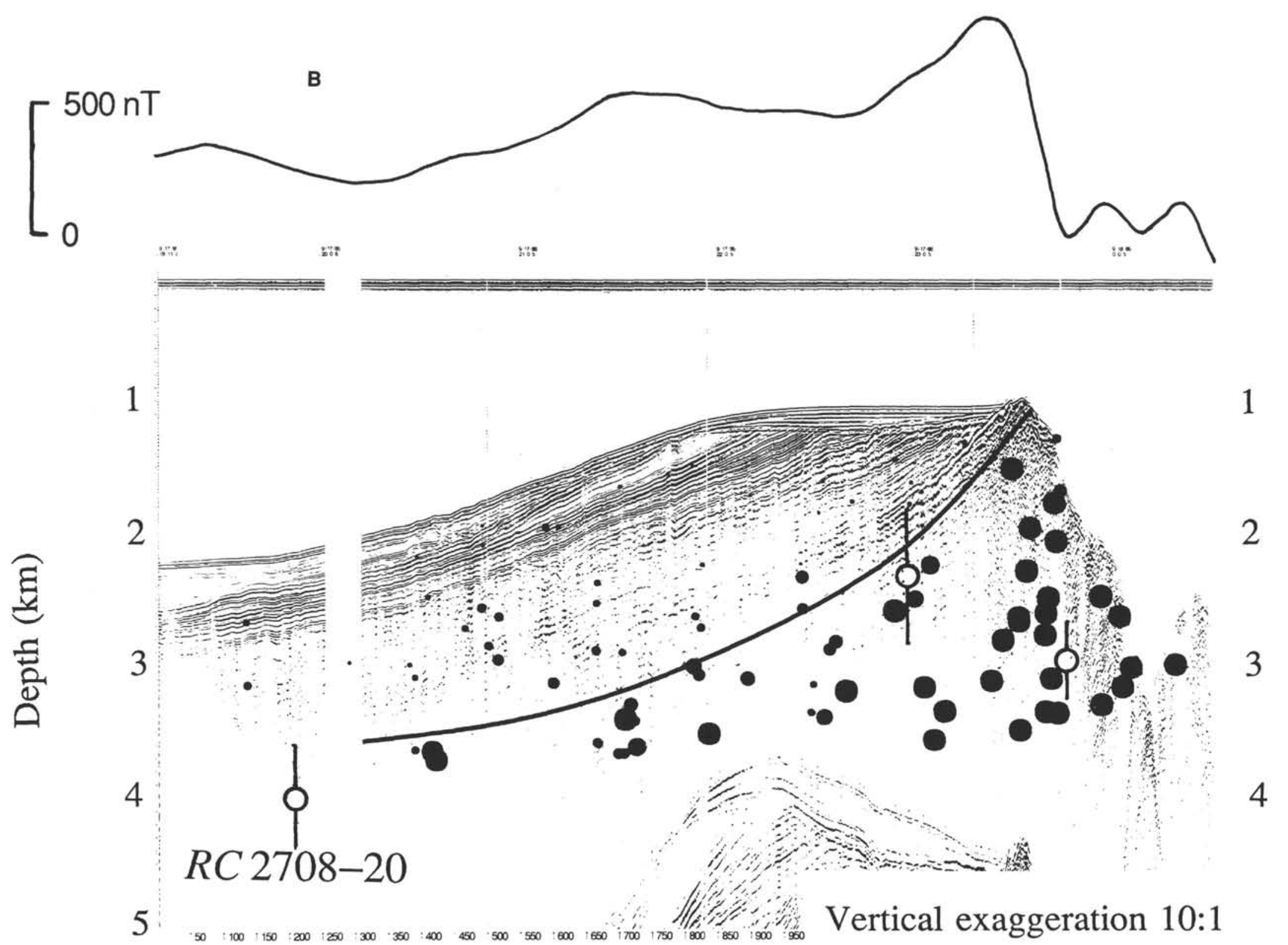

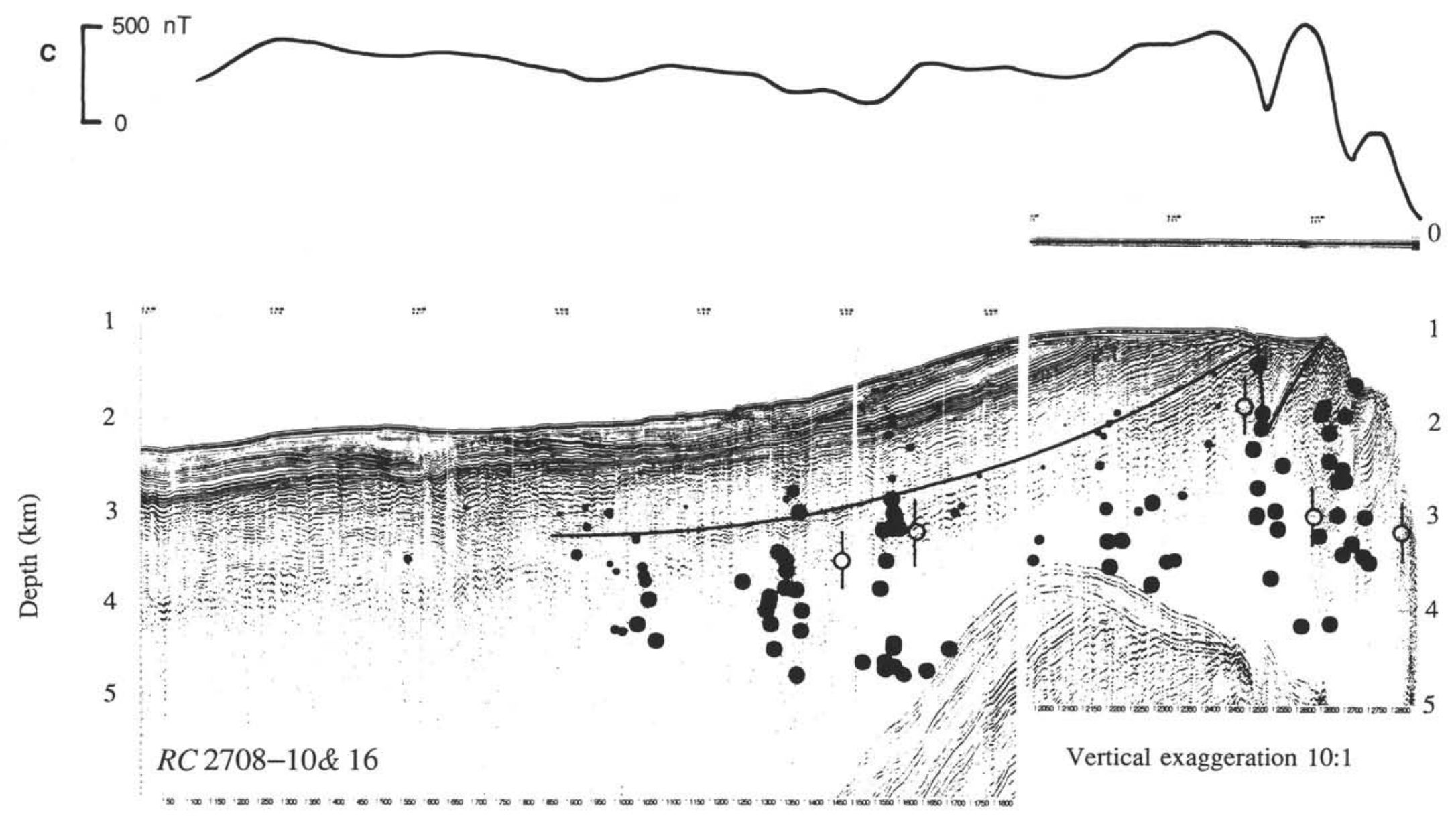

Figure 6 (continued). 
90

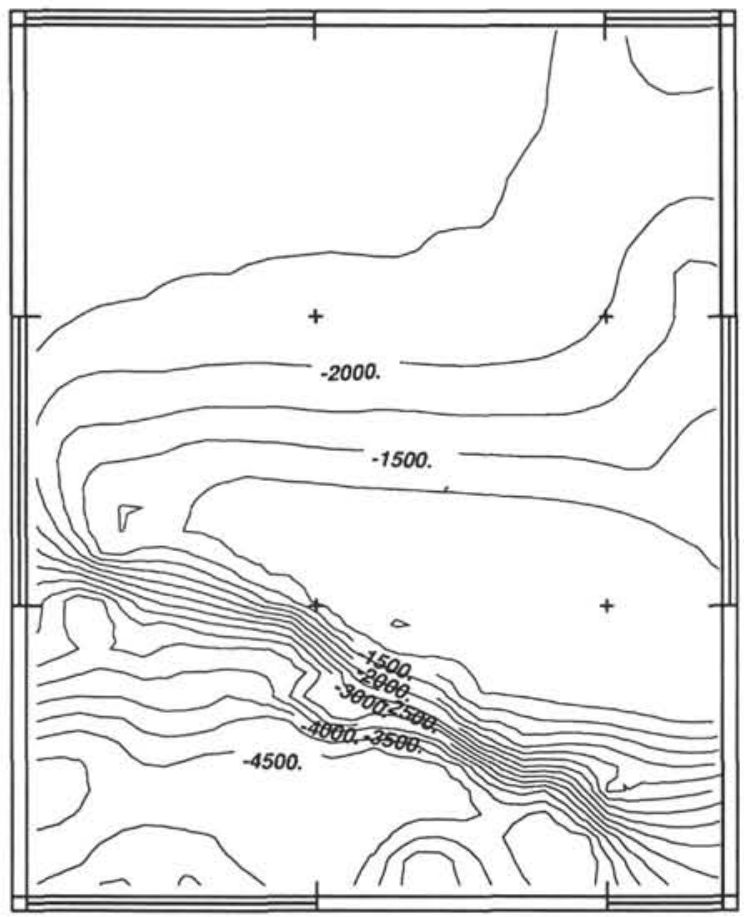

0 30
60
B

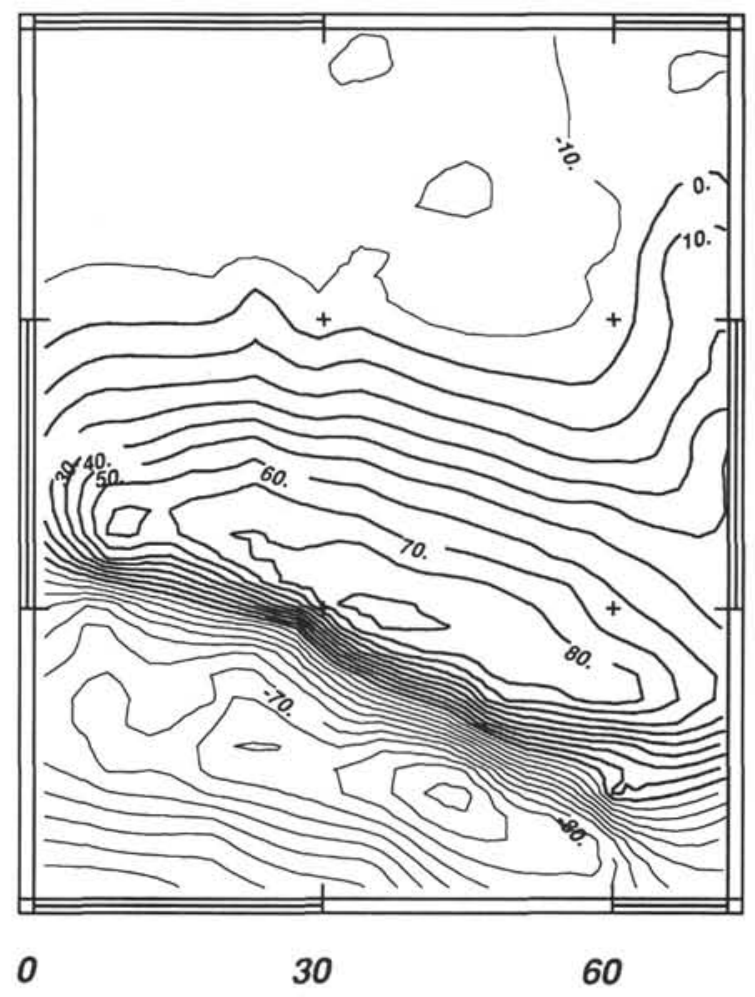

Figure 7. Topography (A) and observed free-air gravity (B) represented as geographical grids but otherwise similar to Figure 3 . The origin is the lower lefthand corner of the map with the $x$ and $y$ coordinates being expressed in terms of arc minutes. The grid spacing is $2^{\prime} \times 2^{\prime}$. Contour interval for the topography and the gravity is $250 \mathrm{~m}$ and $10 \mathrm{mgal}$, respectively. With respect to the gravity, the change in line width is the zero contour.

oceanic crust of the Southeast Indian Ridge system and the pre-rift oceanic crust comprising Broken Ridge. This region is tectonically equivalent to a passive continental margin, with a well-defined rift basin and pre-rift/post-rift oceanic crust boundary (or new crust/old crust boundary). The boundary is marked by magnetic anomaly 18 , the first magnetic anomaly of the Southeast Indian Ridge spreading system and thus dates the transition from rifting to drifting.

The amplitude and wavelength of the gravity difference, north to south across the study area (Fig. 8B), is consistent with a flexural origin for Broken Ridge. In contrast, crustal thickening, perhaps associated with magmatic underplating under Broken Ridge, would be associated with a gravity decrease from north to south. Another possibility, that of a thermal origin for Broken Ridge, must be carefully assessed. The general explanation for rift flank uplift currently in vogue in the literature is that it is due to either lateral heat flow (Stern and ten Brink, 1989), small-scale convection (Buck, 1986), or depth-dependent lithospheric extension in which the mantle thinning component is spatially wider than the region of crustal extension (e.g., White and McKenzie, 1988). A heat source within the mantle will induce isostatic uplift of the overlying crust. Further, the Moho and surface topographies will be parallel. We can discount a thermal origin for Broken Ridge for the following reasons:

1. A heat source within the mantle would represent a negative density contrast and as such, its gravity effect will "compete" with the gravity effect of the uplifted basement and Moho. The resultant free-air gravity anomaly would be characterized by a low amplitude.
2. The present-day heat flow across Broken Ridge is consistent with its age. Thus, any thermal anomaly that might have existed in the Eocene has now dissipated.

3. Given that Broken Ridge was uplifted by $2.5 \mathrm{~km}$ in the Eocene, this magnitude of uplift cannot be produced by a thermal mechanism given reasonable lithospheric thicknesses (i.e., $\leq 125$ km; Weissel and Karner, 1989). We conclude, therefore, that the Moho beneath Broken Ridge is elevated beneath the highest part of the ridge instead of being depressed as required by an Airy compensation model.

Once the gravity effect of the Moho has been isolated (i.e., Fig. $8 \mathrm{~B})$, equation 1 can be rearranged to determine the topographic relief on the Moho for a given density contrast for $n=1$ (Fig. 9). That is,

$$
F[h(x, y)]=-\frac{F[\Delta g(x, y)]}{2 \pi \gamma \Delta \rho} e^{|\bar{k}| z_{o}},
$$

where $\Delta \rho$ is the density contrast between the crust and mantle and assumed to be $2.8 \mathrm{~g} / \mathrm{cm}^{3}-3.33 \mathrm{~g} / \mathrm{cm}^{3}$. As can be seen in equation 2 , the downward continuation operator will accentuate short-wavelength information and will eventually become unstable. Consequently, we calculate the minimum topographic relief consistent with the observed gravity difference shown in Figure $8 \mathrm{~B}$. This is obtained by setting $z_{o} \rightarrow 0$ in equation 2 and is equivalent to using a simple Bouguer slab approximation. As can be seen in Figure 9, the approximate 60-mgal change observed in the gravity difference across the ridge (Fig. 8B) 
A

90

30

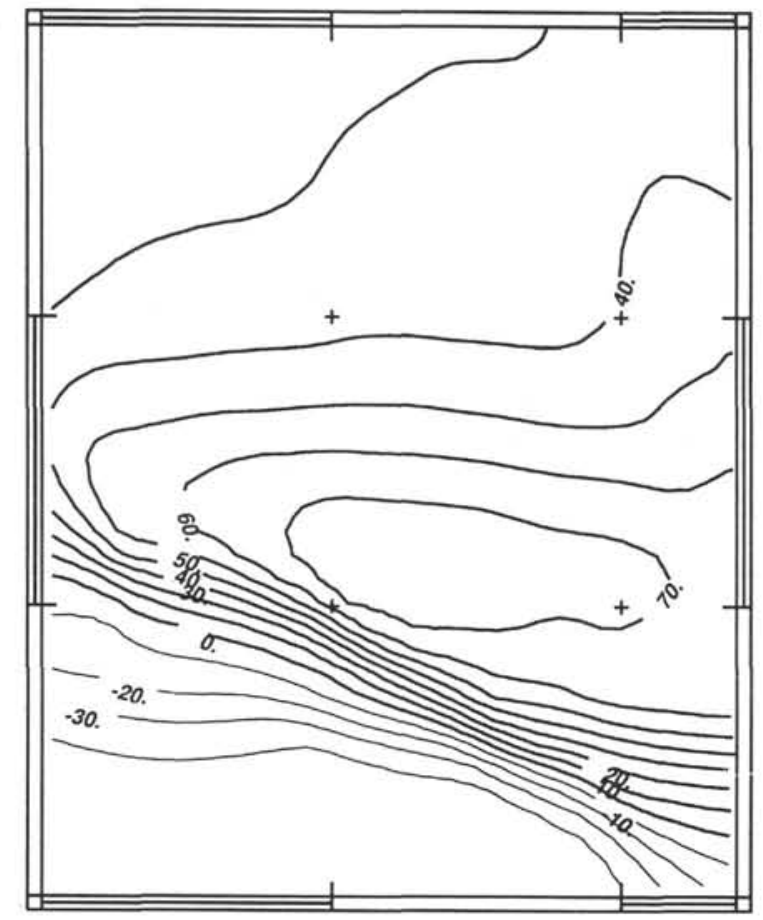

0

30

60
B

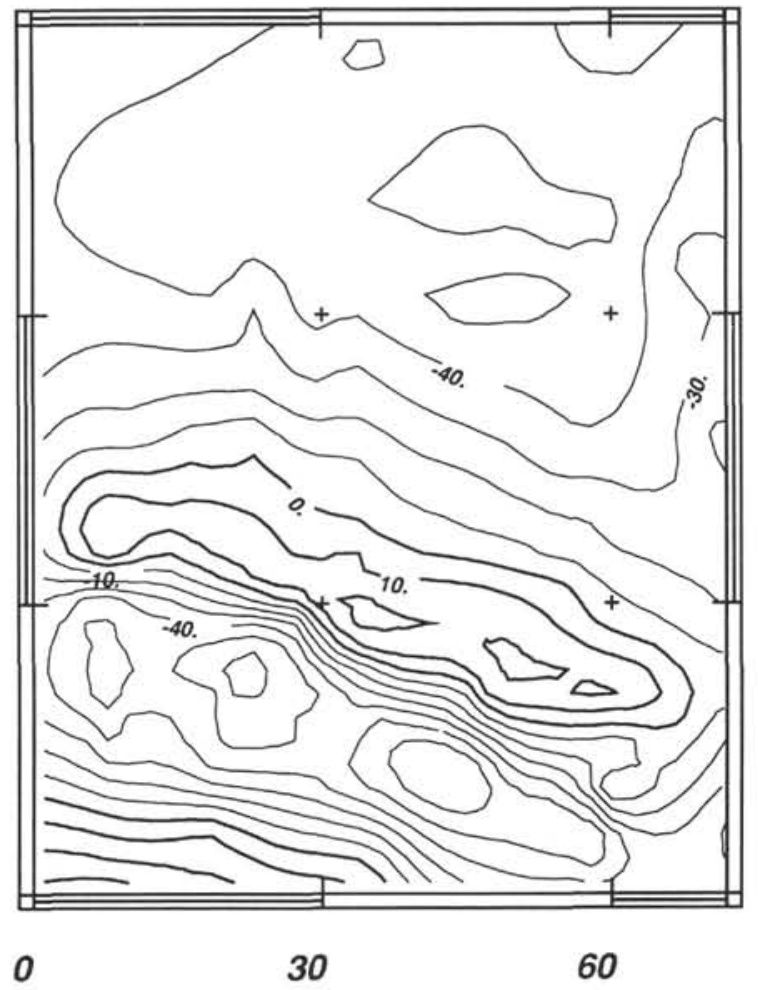

Figure 8. A. Gravity effect of the topography. B. Difference between the observed free-air gravity and the gravity effect of the topography. Contour interval for both maps is $10 \mathrm{mgal}$. The gravity differences are characterized by (1) a gentle increase from the north toward the Broken Ridge escarpment in the south for which the 60 -mgal variation is equivalent to a Moho uplift of $2.7 \mathrm{~km}$, and (2) an intense 60 -mgal negative between the escarpment and the new crust/old crust boundary.

implies a Moho relief of $\approx 2.7 \mathrm{~km}$. The smoothly varying but asymmetric shape of the predicted Moho relief north of the Broken Ridge escarpment (i.e., the rift flank) is typical of flexurally controlled rift flanks as modeled in other rift basins (e.g., Rhinegraben; Weissel and Karner, 1989).

The large negative gravity difference associated with the "rift basin" between the southern escarpment of Broken Ridge and the new ocean/old ocean boundary is a very important result. First, note that the oldest crust of the Southeast Indian Ridge system is at a shallower depth than the immediately adjacent, and thus younger, crust of the same system. Apparently, the oceanic crust of the Southeast Indian Ridge that forms part of the new ocean/old ocean boundary has had a more complicated subsidence history than the usual $\sqrt{\text { time }}$. Second, the large negative amplitude of the gravity difference (Fig. 8B) suggests that the floor of the rift basin is significantly deeper than the adjacent ocean crust. This is surprising because during extension and formation of the new ocean/old ocean boundary, we should expect that the temperature structure, and thus subsidence, of the breached old crust and new oceanic crust to be similar. Further, the gravity difference maximum on the summit of Broken Ridge ( $60 \mathrm{mgal})$ is approximately equal to the gravity difference minimum associated with the rift basin suggesting that the two features may in fact be related. We will see later that the greater depth of the rift basin relative to the new ocean/old ocean boundary and the gravity maximum/minimum relationship is the consequence of extending a lithosphere with a finite flexural strength.

We explore the significance of the preceding observations using a two-dimensional thermo-mechanical model for the devel- opment of Broken Ridge and the adjacent crust of the Southeast Indian Ridge. For convenience, we assume that the kinematics of crustal extension $\delta(x)$ and lithospheric mantle extension $\beta(x)$ can be described using the following Gaussian distributions:

$$
\delta(x)=\delta_{o} e^{-x^{2} / \sigma_{c r u s t}^{2}}
$$

and

$$
\beta(x)=\beta_{o} e^{-x^{2} / \sigma_{\text {mantle }}^{2}} .
$$

where $\delta_{o}=3, \sigma_{\text {crust }}=30 \mathrm{~km}, \beta_{o}=1.5$, and $\sigma_{\text {mantle }}=30 \mathrm{~km}$. The crustal stretching factor reduces a pre-extension crustal thickness of 18 to 6 $\mathrm{km}$, the presumed thickness of normal oceanic crust. Based on the modeling by Weissel and Karner (1989), the pre-rift lithospheric thickness is assumed to be $60 \mathrm{~km}$. Any modeled topography that became emergent during the rifting process is assumed eroded and flexurally adjusted. Flexural isostasy was maintained during rifting, erosion, and in the post-rift stage by "tracking" the depth to the $450^{\circ} \mathrm{C}$ isotherm (Weissel and Karner, 1989). Thus, the pre-rift flexural strength of Broken Ridge is $\approx 20 \mathrm{~km}$. To correctly model the thermal and mechanical behavior of the Southeast Indian Ridge at the time of emplacement (i.e., at the end of rifting), $\delta$ was set to 3 and $\beta$ to 9999.

Figure 10 summarizes our modeled topography and gravity results for the Broken Ridge region. There is excellent agreement between the modeled and observed topography and free-air gravity anomaly across Broken Ridge and the boundary between the Southeast Indian Ridge system and crust comprising Broken 


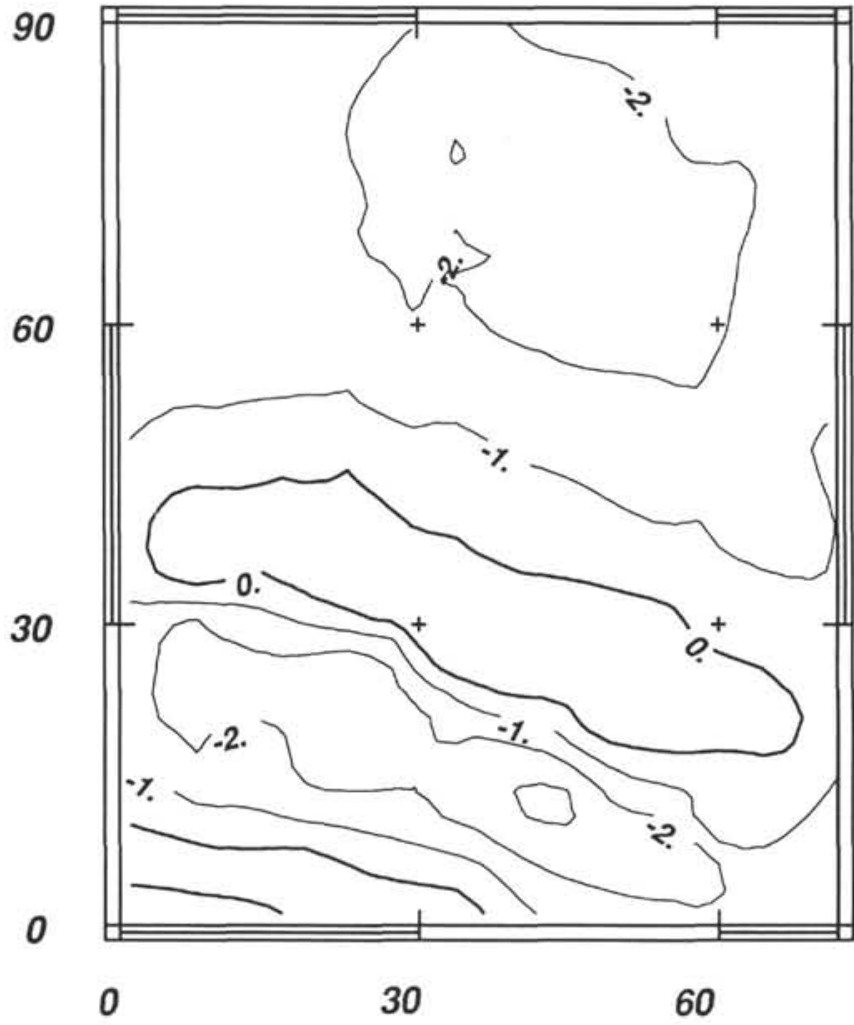

Figure 9. Predicted Moho topography across Broken Ridge using equation 2 with $z_{o}$ set to zero and an assumed density contrast between basement and mantle of $0.53 \mathrm{~g} / \mathrm{cm}^{3}$. The $=60$-mgal variation in the gravity difference across Broken Ridge (Fig. 8B) implies a Moho relief of $\approx 2.7$ $\mathrm{km}$. The amplitude and general shape of this Moho relief is similar to the basement relief independently determined from magnetic depth estimates using Werner deconvolution.

Ridge. From this modeling we make the following observations (Fig. 10):

1. Broken Ridge can be successfully modeled as the flexural rebound of the lithosphere engendered by the rifting of thickened oceanic crust. As such, it is a permanent feature if protected from erosion.

2. Part of an associated rift basin is preserved south of the Broken Ridge escarpment, but has been partly infilled by sediments. Our modeling suggests that this basin is $1500-2000 \mathrm{~m}$ greater in depth than the adjacent Southeast Indian Ridge. This sediment is most likely the detritus produced when Broken Ridge was subaerially exposed during rifting (Driscoll et al., 1989). The same unloading responsible for the rift flank topography is also responsible for the formation of this rift basin. The fact that the negative gravity difference of the rift basin is in approximate balance with the positive gravity difference from the summit of Broken Ridge is a consequence of flexural strength during rifting.

3. The apparent uplift of the oldest sections of the Southeast Indian Ridge can be adequately explained as a "flexural coupling" effect across the new ocean/old ocean boundary. All three observations, the uplift of Broken Ridge, the existence of a relatively deep rift basin, and the anomalous subsidence close to the new ocean/old ocean boundary, attest to the finite flexural strength of the rifted lithosphere during and after extension despite localized fracturing of the crust by crustal-scale normal faults and high heat-flow regimes during the establishment of the Southeast Indian Ridge spreading system.

\section{CONCLUSIONS}

From the analysis of magnetic and gridded free-air gravity data across Broken Ridge, we make the following conclusions:

1. Werner deconvolution and Peters half-slope magnetic depth estimates, when superposed onto depth-converted seismic-reflection records (lines 6,10 and 16 , and 20 ), suggest that the maximum thickness of pre-, syn-, and post-rift sediments on Broken Ridge is $1000-1500 \mathrm{~m}$. Magnetic basement dips gently north across Broken Ridge, with a marked increase in dip toward the southern escarpment. The total variation of basement topography across Broken Ridge north of the crest is $\approx 2000-2800 \mathrm{~m}$.

2. The large magnetization estimates from both shallow and deep sources along the southern escarpment of Broken Ridge suggest that the escarpment consists of basaltic rock.

3 . The amplitude of the free-air gravity anomaly, when corrected for the three-dimensional gravitational effect of the topography, increases from north to south across Broken Ridge. The change in gravity is $\approx 60 \mathrm{mgal}$ and implies a maximum Moho uplift of $\approx 2.7 \mathrm{~km}$.

4. The Moho topography across Broken Ridge, as inferred from the gravity analysis, is in agreement with the basement topography as obtained from Werner deconvolution. The Moho beneath Broken Ridge is elevated beneath the highest part of the ridge instead of being depressed as required by an Airy compensation model. Thus, the magnitude and shape of the basement and Moho topographies are consistent with the production of Broken Ridge by the unloading and flexural rebound of the lithosphere during extension.

5. The large gravity difference negative across the zone of extended crust between the escarpment and the new ocean/old ocean boundary defines a "rift basin," partly infilled with sediment and having a maximum depth of $\approx 1.5 \mathrm{~km}$ below the adjacent Southeast Indian Ridge seafloor.

6. Southeast Indian Ridge crust immediately adjacent to the rift basin is shallower (by $\approx 1000 \mathrm{~m}$ ) than it should be given its age. This uplift appears to be induced by mechanical coupling and differential subsidence across the new ocean/old ocean boundary.

7. The mechanical support of Broken Ridge and the uplift of the Southeast Indian Ridge ocean crust both attest to a finite flexural strength of the lithosphere during and after rifting despite localized fracturing of the crust by crustal-scale normal faults and high heat-flow regimes associated with the establishment of the Southeast Indian Ridge spreading system.

\section{ACKNOWLEDGMENTS}

We would like to take this opportunity to thank Jeffrey Weissel for discussions concerning the ideas of flexural coupling across ocean/continent boundaries. Kim Klitgord, David Sandwell, and Jeffrey Weissel critically reviewed the manuscript and their comments are appreciated. Major support for this work was from USSAC/JOI through TAMRF P.O. \#20258. Lamont-Doherty Geological Observatory Contribution 4757.

\section{REFERENCES}

Bott, M.H.P., 1967. Solution of the linear inverse problem in magnetic interpretation with application to oceanic magnetic anomalies. Geophys. J. R. Astron. Soc., 13:313-323.

Buck, W. R., 1986. Small-scale convection induced by passive rifting: the cause for uplift of rift shoulders. Earth Planet. Sci. Lett., 77: $362-372$.

Driscoll, N. W., Karner, G. D., Weissel, J. K., and Shipboard Scientific party, 1989. Stratigraphic and tectonic evolution of Broken Ridge from seismic stratigraphy and Leg 121 drilling. In Peirce, J., Weissel, J., et al., Proc. ODP, Init. Repts., 121: College Station, TX (Ocean Drilling Program), 71-91. 
Francis, T.J.G., and Raitt, R. W., 1967. Seismic refraction measurements in the southern Indian ocean. J. Geophys. Res., 72:3015-3041.

Grant, F. S., and West, G. F., 1965. Interpretation Theory in Applied Geophysics: New York (McGraw-Hill).

Hartman, R. R., Teskey, D. J., and Friedberg, J., 1971. A system for rapid digital aeromagnetic interpretation. Geophysics, 36:891-918.

Hsü, H. D., and Tilbury, L. A., 1977. A magnetic interpretation program based on Werner deconvolution. Aust. BMR, Rec. no. 1977/50.

Jain, S., 1976. An automatic method of direct interpretation of magnetic profiles. Geophysics, 41:531-541.

Klitgord, K. D., and Behrendt, J. C., 1979. Basin structure of the U.S. Atlantic Margin. In Watkins, J. S., Montadert, L., and Wood-Dickerson, P. (Eds.), Geological and Geophysical Investigations of Continental Margins. AAPG Mem., 29:85-112.

Parker, R. L., 1973. The rapid calculation of potential anomalies. J. Geophys. R. Astron. Soc., 31:447-455.

Peirce, J., Weissel, J., et al., 1989. Proc. ODP, Init. Repts., 121: College Station, TX (Ocean Drilling Program).

Peters, L. J., 1949. The direct approach to magnetic interpretation and its practical application. Geophysics, 14:290-320.
Royden, L., and Keen, C. E., 1980. Rifting processes and thermal evolution of the continental margin of eastern Canada determined from subsidence curves. Earth Planet. Sci. Lett., 51:343-361.

Smith, W.H.F., and Wessel, P., 1990. Gridding with continuous curvature splines in tension. Geophysics, 55:293-305.

Stern, T. A., and ten Brink, U. S., 1989. Flexural uplift of the Transantarctic Mountains. J. Geophys. Res., 94:10315-10330.

Weissel, J. K., and Karner, G. D., 1989. Flexural uplift of rift flanks due to mechanical unloading of the lithosphere during extension. J. Geophys. Res., 94:13919-13950.

Werner, S., 1953. Interpretation of magnetic anomalies at sheet-like bodies. Sveriges Geologiska Undersok., Ser. C.C. Arsbok 43, N:06.

White, N. J., McKenzie, D. P., 1988. Formation of the "steer's head" geometry of sedimentary basins by differential stretching of the crust and mantle. Geology, 16:250-253.

Date of initial receipt: 6 April 1990

Date of acceptance: 25 September 1990

Ms 121B-120

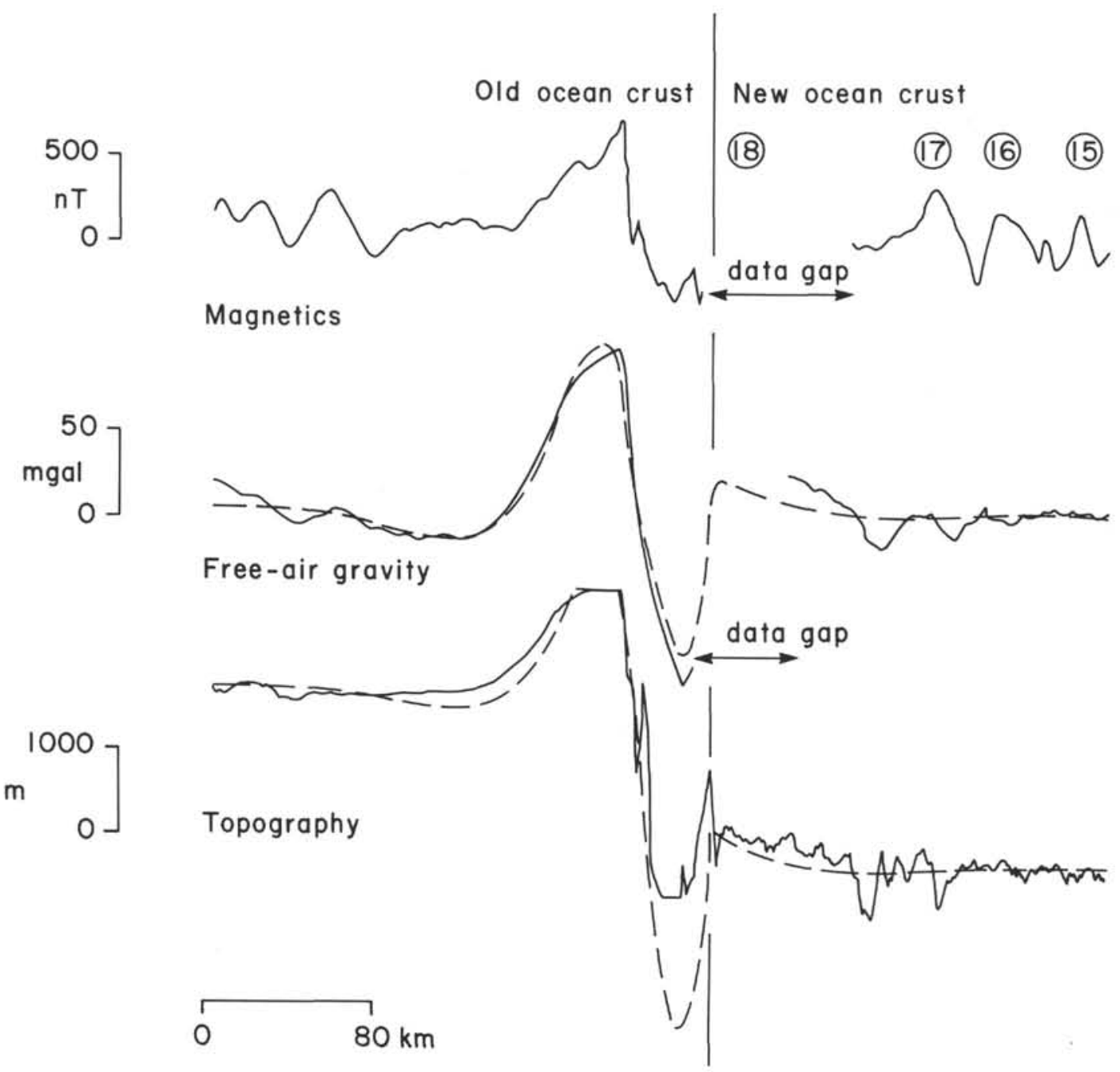

Figure 10. Thermo-mechanical model for the development of the Broken Ridge region. The extension parameters, $\delta(x)$ and $\beta(x)$, were approximated as Gaussian functions with $\delta_{\max }$ and $\beta_{\max }$ defining the new crust/old crust boundary. The crustal thickness of Broken Ridge was assumed to be $18 \mathrm{~km}$. The thermal and mechanical properties of the Southeast Indian Ridge were approximated by $\delta(x)=\delta_{\max }=3$ (given that normal ocean crust is $6 \mathrm{~km}$ thick) and $\beta(x)=\beta_{\max }=9999$. As a consequence of rifting and the flexural unloading and rebound of the lithosphere, Broken Ridge was created. During the thermal phase of subsidence, regional subsidence resulted in the resubmergence of Broken Ridge. Mechanical coupling across the new crust/old crust boundary tends to initially retard the subsidence of the Southeast Indian Ridge crust. The new crust/old crust boundary is defined by the interruption of recognizable seafloor spreading magnetic anomalies $15-18$ (circled). 


\section{APPENDIX}

Theory of Werner Deconvolution

Consider a magnetic anomaly measured along the horizontal $x$-axis caused by a general two-dimensional distribution of magnetization of constant direction striking perpendicular to the $x$-axis. The $z$-axis points vertically downward and the observed total magnetic anomaly at $(x, 0)$ is $T(x)$. In addition, suppose that the distribution of magnetization causing the anomaly may be represented by a closed body whose upper and lower surfaces are $\eta_{1}(\xi)$ and $\eta_{2}(\xi)$ with $\xi$ paralleling the $x$-axis. The intensity of magnetization is given by $J(\xi)$. The total magnetic field is determined by the convolution (e.g., Bott, 1967):

$$
T(x)=\int_{-\infty}^{+\infty} J(\xi) K\left(\eta_{1}, \eta_{2},[x-\xi] d \xi,\right.
$$

where $K$ is a kernel that is dependent primarily on the geometry of the distribution of magnetization. Simplifying the magnetization geometry increases the ease with which equation $\mathrm{A} 1$ can be evaluated.

For Werner deconvolution, the strike length and depth of the causative body are assumed to be infinite (i.e., $\eta_{2} \rightarrow \infty$ ) while the width of the body is assumed to be either (1) finite, representing a dike (the "tabular" body of Grant and West, 1965 ) or (2) approaching zero such that it represents an interface between two regions of differing magnetic susceptibility (the "ribbon" model of Grant and West, 1965). For practical purposes, bodies whose widths are comparable to their depth (i.e., $\eta_{1}$ ) from the observation plane represent dikes while bodies of considerable lateral extent approximate an interface. Werner (1953) recognized that the usual approach to magnetic interpretation, that of analyzing discrete anomalies using such parameters as maxima, minima, inflection points, or other intrinsic properties of the observed magnetic anomaly profile, was problematic because of the interference of adjacent anomalies and the effect of noise (e.g., diumal variations, non-two-dimensionality, etc.). In contrast, Werner deconvolution uses simple models for the source and source/noise interference to determine the depth to the top of the causative magnetic bodies, their intensity, and angle of magnetization. Assuming a dike model, equation $\mathrm{Al}$ can be evaluated to give

$$
T(x)=\frac{A h+B\left(x-x_{o}\right)}{\left(x-x_{\mathrm{o}}\right)^{2}+h^{2}}
$$

where $T(x)$ is the total magnetic field intensity at position $x, h$ is the depth to the top of the interface, $x_{o}$ is the horizontal position of the dike (its midpoint), and $A$ and $B$ are parameters related to the magnetic properties across the interface. In particular, $\left(A^{2}+B^{2}\right)^{1 / 2}$ and $\tan ^{-1}(A / B)$ are the susceptibility contrast and angle of magnetization, respectively. Equation $A 2$ is valid for all semi-infinite, homogerieous, thin-sheet bodies, whatever their strike, dip, remanent magnetization, or magnetic latitude (Hartman et al., 1971). We follow Hsü and Tilbury (1977) in defining the total magnetic field that results from the interaction of two sources and a quadratic-form background:

$$
\begin{aligned}
T(x)= & \frac{A_{1} h_{1}+B_{1}\left(x-x_{l}\right)}{\left(x-x_{1}\right)^{2}+h_{1}^{2}}+\frac{A_{2} h_{2}+B_{2}\left(x-x_{l}\right)}{\left(x-x_{1}\right)^{2}+h_{1}^{2}} \\
& +\left[a_{o}+a_{1} x+a_{2} x^{2}\right] .
\end{aligned}
$$

The first two terms on the right of this equation define the magnetic field intensity at $x$ produced by the interaction of two sources. The third term represents the assumed form of any background noise or long-wavelength information not explained by the first two terms. Parameters $A_{1}, B_{1}, x_{1}, h_{1}$, and $A_{2}, B_{2}, x_{2}, h_{2}$ correspond to $A_{o}, B_{o}, x_{o}, h_{o}$ in equation $\mathrm{A} 2$.

Our objective is to determine the unknown parameters $\left(A, B, x_{0}, h\right)$ of the magnetic sources that produce the observed magnetic field. To solve analytically for the 11 unknowns in equation $\mathrm{A} 3$, we will require 11 data points. Consequently, we will have a "window of interpretation," consisting of 11 data points, that "moves" through the observed magnetic data profile solving each time for the magnetic parameters. Equation $\mathrm{A} 3$ can be linearized into the following form (Hsü and Tilbury, 1977):

$$
\begin{aligned}
x^{4} T= & C_{1} x^{3} T+C_{2} x^{2} T+C_{3} x T+C_{4} T+C_{5} x^{2}+C_{6} x \\
& +C_{7}+C_{8} x^{3}+C_{9} x^{4}+C_{10} x^{3}+C_{11} x^{6},
\end{aligned}
$$

where

$$
\begin{aligned}
C_{1}= & 2 x_{1}+2 x_{2} \\
C_{2}= & -W_{1}^{2}-W_{2}^{2}-4 x_{1} x_{2} \\
C_{3}= & 2 x_{1} W_{2}^{2}+2 x_{2} W_{1}^{2} \\
C_{4}= & -W_{1}^{2} W_{2}^{2} \\
C_{5}= & A_{1} h_{1}+A_{2} h_{2}-B_{1} x_{1}-B_{2} x_{2}-2 B_{1} x_{2}-2 B_{2} x_{1}-C_{2} a_{o} \\
& +C_{3} a_{1}-C_{4} a_{2} \\
C_{6}= & B_{1} W_{2}^{2}+B_{2} W_{1}^{2}+2 x_{1} x_{2}\left(B_{1}+B_{2}\right)-2 A_{1} h_{1} x_{2}-2 A_{2} h_{2} x_{1} \\
& -C_{3} a_{v}-C_{4} a_{1} \\
C_{7}= & A_{1} h_{1} W_{2}^{2}+A_{2} h_{2} W_{1}^{2}-B_{2} x_{2} W_{1}^{2}+W_{1}^{2} W_{2}^{2} a_{o} \\
C_{8}= & B_{1}+B_{2}-C_{1} a_{o}-C_{2} a_{1}-C_{3} a_{2} \\
C_{9}= & a_{o}-C_{1} a_{1}-C_{2} a_{2} \\
C_{10}= & a_{1}-C_{1} a_{2} \\
C_{11}= & a_{2}
\end{aligned}
$$

and

$$
\begin{aligned}
& W_{1}^{2}=x_{1}^{2}+h_{1}^{2} \\
& W_{2}^{2}=x_{2}^{2}+h_{2}^{2} .
\end{aligned}
$$

The relationships between the original unknowns and the preceding coefficients can be rewritten in matrix and vector form thus:

$$
\underline{C}=[\mathrm{A}]^{-1} \underline{\chi^{4} T}
$$

To solve for $C$, we have to compute the inverse of matrix $[A]$. If matrix $[A]$ is not singular (i.e., $\operatorname{det} A \neq 0$ ) or ill-conditioned, then $C$ can be uniquely determined.

By successive back-substitution, we can solve for $a_{o}, a_{1}$, and $a_{2}$, viz.,

$$
\begin{aligned}
& a_{2}=C_{11} \\
& a_{1}=C_{10}+C_{1} a_{2} \\
& a_{o}=C_{9}+C_{1} a_{1}+C_{2} a_{2} .
\end{aligned}
$$

To determine $x_{1}, x_{2}, h_{1}$, and $h_{2}$, we simply use the equations:

$$
\begin{aligned}
2 x_{1}+2 x_{2} & =C_{1} \\
-W_{1}^{2}-W_{2}^{2}-4 x_{1} x_{2} & =C_{2} \\
2 x_{1} W_{2}^{2}+2 x_{2} W_{1}^{2} & =C_{3} \\
-W_{1}^{2} W_{2}^{2} & =C_{4},
\end{aligned}
$$

where [equation] and [equation] were defined in equation A6. Using equation A5, we can produce a polynomial equation $P$ in terms of $x_{1}$ viz.,

$$
\begin{aligned}
4 P\left(x_{1}\right)= & {\left[C_{2}\left(C_{1}-2 x_{1}\right)+2 x_{1}\left(C_{1}-2 x_{1}\right)^{2}+C_{3}\right] } \\
& {\left[2 C_{2} x_{1}+2 x_{1}^{2}\left(C_{1}-2 x_{1}\right)+C_{3}\right] } \\
& -2 C_{4}\left(4 x_{1}-C_{1}\right)^{2},
\end{aligned}
$$

the roots of which are estimates of $x_{1}$. Given $x_{1}$, then

$$
\begin{aligned}
x_{2} & =C_{1} / 2-x_{1} \\
W_{1}^{2} & =\frac{x_{1}\left(C_{2}+4 x_{1} x_{2}\right)+C_{3} / 2}{x_{2}-x_{1}} \\
W_{2}^{2} & =\frac{x_{2}\left(C_{2}+4 x_{1} x_{2}\right)+C_{3} / 2}{x_{1}-x_{2}} .
\end{aligned}
$$


Thus,

$$
\begin{aligned}
& h_{1}=\left(W_{1}^{2}-x_{1}^{2}\right)^{1 / 2} \\
& h_{2}=\left(W_{2}^{2}-x_{2}^{2}\right)^{1 / 2} .
\end{aligned}
$$

Once $a_{o}, a_{1}, a_{2}, x_{1}, x_{2}$, and $h_{2}$ are determined, $A_{1}, B_{1}, A_{2}$, and $B_{2}$ can be obtained by the least-squares method.
Thus far, the mathematics presented assumed that the source of the magnetic anomaly can be represented by a dike. However, the horizontal derivative of the total magnetic intensity over an interface has the same mathematical form as that of a dike (e.g., Hsü and Tilbury, 1977; Jain, 1976). Consequently, the same mathematics can be used to investigate the interface model except that we will be working with the derivative of the magnetic profile. 